\title{
La Decisión Judicial Limitada
}

\section{Wilson Yesid Suárez Manrique}

Maestría en Hermenéutica jurídica y Derecho, Universidad Industrial de Santander. Especialización en Derecho Procesal, Universidad Santo Tomás Bucaramanga (Colombia), Abogado, Universidad Santo Tomás, Bucaramanga (Colombia). Coordinador Especialización en Derecho Constitucional, Universidad Santo Tomás, Bucaramanga (Colombia). Docente Universidad Santo Tomás Bucaramanga (Colombia)

E-mail:wilsonyesidsuarez@gmail.com

\section{Resumen}

Actualmente no existe una teoría unitaria, realista y comprensiva de como deciden los jueces. Este artículo pretende contribuir en la discusión mediante dos estrategias: primera: la presentación de la decisión judicial como un caso particular e institucionalizado de la Teoría de la Elección Racional; segunda: la noción de las normas sociales judiciales, como un complemento y condicionante de la decisión judicial.

Palabras clave: Decisión judicial, Racionalidad, Límites, Normas sociales.

\section{Abstract}

There is currently no unitary theory, realistic and comprehensive as the judges decide. This article aims to contribute to the discussion via two strategies. First, the presentation of the court decision as a particular case and institutionalized Rational Choice Theory. Second, the notion of judicial social norms as a supplement and conditioning of the court decision.

Keywords: Court decision, Rationality, Boundaries, Social norms.

\section{Résumé}

Iln'existeactuellementaucunethéorieunifiée, réaliste et globale de la façondont les jugesdécident. Cetarticle vise à contribuer à la discussion à traversdeuxstratégies. Toutd'abord, la présentation de la décision du tribunal comme une théorieinstitutionnelleparticulière de Rational cas de choix. Deuxièmement, la notion de normes sociales et judiciairesconditionnécomme un complément de la décisionjudiciaire.

Mots-clés: Décision de la cour, La rationalité, Les limites, Les normes sociales. 

Wilson Yesid Suárez Manrique

\section{INTRODUCCIÓN}

Existe una fuerte creencia de la dependencia que se genera entre el legalismo jurídico y la racionalidad de la función judicial. Se considera que una decisión judicial es racional en cuanto pueda derivarse de normas jurídicas preestablecidas. Ello ayuda, entre otras cosas, a limitar el mito de la discreción judicial. Entre más cercana encuentre una decisión su fundamentación en normas positivas más se aleja de la discrecionalidad judicial. Por tanto, la eliminación de los limitantes que gesta el legalismo puede conllevar, a ampliar el marco de decisión del juez, y con ello se abre la contera a que no existan parámetros claros para el decisor. De forma gráfica, Posner (2011) manifestó que "Iván Karamazov dijo que si Dios no existe todo está permitido, y es muy probable que los juristas teóricos más tradicionales digan que si el legalismo [...] no existe, entonces los jueces lo tienen todo permitido" (p. 11).

La pregunta de si existe el legalismo puede responderse de múltiples maneras; dependiendo el enfoque y el contexto puede darse una respuesta general y otra especifica. De forma específica, la pregunta se perfila mejor si se delimita a un ámbito geográfico y a un tiempo determinado. Es una pregunta cronotópica que se responde mejor desde las diversas experiencias jurídicas (Bajtín, 1989).

De forma general, la pregunta, con un mayor grado de abstracción se responde de manera condicionada: el legalismo existe actualmente pero no de la forma clásica planteada y desarrollada a inicios del siglo XIX. El "legalismo se halla en gran medida confinado a los casos rutinarios" (Posner, 2011, p. 11).

Esta respuesta general tiene la pretensión de ser prudente. No cae en la ingenuidad de querer mostrar al legalismo como una práctica y forma abandonada de entender

* El artículo pertenece al proyecto: Interpretación contractual adecuada. Grupo Neocontitucionalismo y Derecho. Línea: Neoconstitucionalismo y Derecho. Quinta Convocatoria Interna, Universidad Santo Tomás, Bucaramanga (Colombia). 
el derecho. Alguien que desea ser tomado en serio no puede olvidar la importancia que ostenta la ley actualmente a la hora de tomar una decisión. No obstante, tampoco puede entenderse admisible la postura contraria, mediante la cual se pretende restar importancia a otros criterios importantes en las decisiones judiciales, el precedente, los principios del derecho, los postulados constitucionales, las regulaciones trasnacionales, las microregulaciones, la política y hasta las emociones (Berman, 1996).

El presente artículo pretende mostrar cómo la decisión judicial puede explicarse de mejor forma si se le ve como un caso particular de la Teoría de la Elección Racional (TER). Teniendo en cuenta los límites explicativos de la TER y la influencia de las normas sociales en los comportamientos humanos. Para cumplir la finalidad antedicha, el escrito se divide en tres partes: en la primera se describen los modelos "clásicos" de decisión judicial más trascendentales; en la segunda se relatan los presupuestos de la teoría de la elección racional (TER), y se muestra la decisión judicial como discurso particular de las decisiones humanas; y en la tercera parte se reconstruye un modelo de decisión judicial basado en la TER y en sus limitaciones.

\section{LOS MODELOS DE DECISIÓN JUDICIAL}

La presente sección se divide en tres partes: en la primera se realizan cuatro aclaraciones previas en torno a los modelos de decisión judicial; en la segunda se presentan once modelos de decisión judicial; en la tercera se efectúan unas apreciaciones críticas acerca de tales teorías.

\subsection{Aclaraciones previas}

En el presente apartado se efectúan cuatro aclaraciones generales que ayudan a entender de forma más adecuada las distintas. Son aclaraciones muy sencillas y fáciles de entender, por ello se constituyen en previas. Estas aclaraciones hacen alusión a: la doble naturaleza de las teorías, las limitaciones explicativas, la característica copulativa y la falta de claridad conceptual.

La primera aclaración: las teorías pueden tener un uso descriptivo o prescriptivo (Nino, 1974; Alexy, 2002). Las distintas teorías de la decisión judicial ostentan la pretensión de ser descriptivas de una tendencia judicial. Tratan de dar cuenta de un estado de cosas. Su principal finalidad además de decir cómo se comportan los jueces, es la de predecir su tendencia futura. No obstante, en ocasiones se utilizan de forma prescriptiva (López, 2004).

En ocasiones estas teorías se utilizan para decir cómo deben fallar los jueces. No solo se dedican a decir como fallan los jueces sino que hay teorías que nacen o se usan para decir cómo deberían fallar los jueces. Algunas teorías nacieron como descriptivas y se convirtieron en prescriptivas, otras nacieron como prescriptivas y 
se transformaron en descriptivas, otras nacieron y continúan siendo prescriptivas, y puede pensarse en unas que nacieron y continúan siendo descriptivas ${ }^{1}$.

La segunda aclaración: el poder explicativo de las teorías es limitado. No podría pensarse que algún de ellas describe adecuadamente todas las practicas judiciales (Posner, 2011). No hay una teoría enteramente dominante. Además, cada una de ellas puede representar el contexto en el cual se desarrolló y, por ejemplo, variar de forma significativa cuando se trate de decisiones tomadas por uno o varios jueces, en primera instancia o en apelación, dependiendo de la importancia del caso, de la cuantía, la congestión, la calidad de las partes, etc.

En tercer lugar, una descripción global de la práctica judicial, en el mejor de los casos, involucra la relación de una conducta con base en distintas teorías. Lo que quiere decirse es que las distintas teorías pueden agruparse para explicar determinadas conductas. Así pues, la teoría económica y la pragmatista pueden explicar de mejor forma una conducta. En sentido contrario, no hay regla que prohíba agrupar el uso explicativo de cada una de las teorías. La combinación de los distintos modelos conlleva a la existencia de múltiples modelos complejos.

En cuarto lugar: no existe claridad conceptual que permita deslindar plenamente las distintas teorías (Bulygin y Alchourrón, 1987). No puede limitarse con precisión el campo de acción y aplicación de cada una de ellas. En ocasiones una misma conducta puede ser explicada con base en distintas teorías, una decisión judicial puede ser explicada de la misma forma por el pragmatismo y el legalismo.

\subsection{Once tendencias generales}

Las teorías acerca de la decisión judicial pueden ser tantas que un detallado listado desborda el objeto del presente artículo. Desde ya, se anuncia que se dejan por fuera modelos clásicos para ceder el paso a las teorías que se consideran actualmente como las más importantes. Las teorías escogidas son: la legalista, la actitudinal, la constitucionalista, la estratégica, la sociológica, la económica, la pragmática, la social, la ecléctica, la intuicionista y la escéptica. Se deja por fuera la teoría fenomenológica ${ }^{2}$ y la organizacional ${ }^{3}$, por lo reducido del presente escrito y por no ser tan importantes para el cumplimiento del objetivo planteado.

La teoría legalista hunde sus raíces en los dogmas clásicos de los desarrollos formalistas de los inicios del siglo XIX. Según esta tesis las decisiones judiciales se

1 Algunas de las formas de conducta de los jueces y las cuales se pudieron agrupar en teorías descriptivas han sido tomadas luego como prescriptivas.

2 La teoría fenomenológica analiza "la conciencia en primera persona: la experiencia tal como se presenta ella misma a la mente consciente. Así, podríamos preguntarnos cómo se siente uno al tomar una decisión judicial” (Posner, 2011, p. 42).

3 Según la teoría organizacional el juez actúa como agente del gobierno, su mandante, para el que trabaja, ellos ostentan intereses divergentes, el mandante intentará diseñar estructuras organizativas que reduzcan las divergencias. Las medidas legislativas y administrativas que reglamentan la labor judicial se entienden encaminadas a encaminar la labor judicial hacia los intereses del gobierno. 
derivan como casos particulares de normas generales; al estilo del juez autómata, la decisión judicial se constituye como la conclusión de un silogismo en el cual la premisa mayor es la norma, los hechos son la premisa menor, y la sentencia la conclusión (Petev, 1996). El fallo judicial se entiende como la especificación de normas jurídicas en donde no hay espacio para la discrecionalidad del juez ni para valoraciones políticas.

Según la teoría actitudinal, el sentido del fallo del juez depende de sus preferencias políticas. Esta teoría parte de que los jueces son políticos y que sus preferencias determinan el sentido de sus acciones (Posner, 2011). Se trata de una especie de compromiso ideológico. Los jueces liberales estarán más a favor de situaciones como el aborto que los jueces conservadores. Lo importante por aclarar dentro de esta teoría es el grado de obligatoriedad de esas convicciones, las variaciones en los casos controvertidos, las modificaciones en asuntos trascendentales o públicos, etcétera.

Una teoría cercana a la anterior es la concepción constitucionalista. Esta teoría tiene importantes raíces en el constitucionalismo europeo de la segunda posguerra, especialmente en la materialización del derecho, la importancia de los derechos fundamentales, su normatividad, máxima validez jerárquica y en la garantía de la constitución (Elster, 1999; Gargarellay Courtis, 2009; Carbonell y Jaramillo, 2010). La tesis central afirma que los jueces deciden según los mandatos constitucionales; este enfoque se hace patente especialmente a las decisiones de las cortes y tribunales constitucionales.

La teoría estratégica del comportamiento judicial parte del supuesto de que los jueces no siempre deciden como lo harían si no tuvieran que preocuparse por las reacciones que frente a sus decisiones vayan a tener otros jueces (ya sean sus colegas o los jueces de un tribunal superior o inferior), los legisladores y el público ${ }^{4}$. Según esta tesis: el juez se comportará como un estratega en sus decisiones para conseguir lo que desea. En otras palabras: "Sea lo que sea aquello que un juez quiere conseguir, dependerá en un grado considerable de otros individuos de la cadena de autoridades entendida en un sentido amplio" (Posner, 2011, p. 42). Luego ascender, que sus decisiones no se revoque, que sea secundado en un futuro, prestigio, estabilidad laboral, afinidad política, son los determinantes más importantes para la toma de decisiones judiciales.

La teoría sociológica del comportamiento judicial se aplica especialmente en aquellos casos en los cuales la decisión judicial se toma entre varias personas. La tesis central establece que la conformación de las mesas de decisión determina el sentido del "fallo". Una sala de decisión conformada en su mayoría de jueces conservadores decidirá de forma muy distinta que una conformada en su mayoría por liberales.

4 Algunos de los seguidores de esta corriente son economistas o cultivadores de la ciencia política, que consideran que la política es como una lucha entre grupos de interés y que usan la teoría de juegos para llevar a cabo un análisis más fino. Otros estudian las luchas históricas entre el poder judicial y otros poderes del estado (Posner, 2011, p. 42). 
Especialmente esto puede notarse en temas controvertidos como el aborto y la dosis personal. Un caso de presunta discriminación por el color de la piel, puede ser dicho de forma diferente si la sala está conformado en su mayoría por afrodescendientes o si está formado por personas que históricamente no han sido discriminadas.

La teoría psicológica de la decisión judicial, presenta interesantes perspectivas técnicas. Según esta teoría la decisión judicial está guiada, como la mayoría de las acciones humanas, por las preconcepciones y contextos del juez. La decisión puede ser explicada de mejor forma por un psicólogo que por un jurista. La determinación del sentido de un fallo es el producto de vivencias acarreadas por el desarrollo sicogenético de un individuo (Hernández, 2010).

Por su parte, la concepción clásica de la teoría económica de la decisión judicial presupone que el juez es egoísta, racional y maximizador. El juez ostenta determinados objetivos que desea conseguir los cuales son los encargados de guiar sus acciones. "Los «argumentos» (elementos) de la función de utilidad judicial incluyen los ingresos recibidos, el ocio, el poder, el prestigio, la reputación, el autorrespeto, la satisfacción intrínseca a su tarea (retos, estímulos) y las demás recompensas que la gente busca en el trabajo" (Posner, 2011, p. 42).

La teoría pragmatista de la decisión judicial ostenta importante influencias del utilitarismo y de forma más cercana de las reflexiones del pragmatismo jurídico. Esta doctrina afirma que la decisión judicial no se fundamenta en normas legales sino en las consecuencias de la decisión. Es decir, se cambia la concepción clásica en la cual el fundamento de los juicios se halla en las premisas, y, en su lugar, el fundamento se establece en las consecuencias de los juicios.

La corriente social parte de los desarrollos del marxismo heterodoxo representado en las posturas del uso alternativo del derecho en Italia y Francia (Pashukanis, 1976; Pérez, 1996). Según esta posición, que en un principio ostentaba un carácter prescriptivo, en los momentos de indeterminación judicial el juez debe tomar la decisión que mejore la parte débil del conflicto jurídico. La tesis central de esta corriente es que los jueces en sus decisiones tratan de favorecer a la parte débil, a los más desventajados de la sociedad. Este movimiento ha ganado terreno especialmente en el constitucionalismo latinoamericano de sociedades periféricas, en donde se ha hecho importante la labor judicial a efectos de buscar una igualdad material.

La teoría ecléctica es representada especialmente por Posner (2011). Esta tesis parte del presupuesto que la toma de decisión del juez obedece a una malgama de factores de diferente tipo: cognitivos, económicos y sociológicos. Sus concepciones acerca de la decisión judicial se basan en la unión de diversas teorías mediante las cuales se pretende presentar una síntesis de los modelos clásicos, con el modelo económico y laboral en donde también se tengan en cuenta las emociones del juez como incentivos a la hora de tomar decisiones.

El modelo intuicionista deviene de la aplicación de la psicología, la pedagogía y la antropología en los procesos cognitivos y de decisión humana. Se muestra esta posición como un modelo alternativo a la concepción lógica del derecho a la cual 
quiere contraponerse. Según el núcleo central de esta tesis las providencias judiciales no obedecen a procesos lógicos sino a procesos intuicionistas, en esta orbita se hace importante la lógica operativa, específicamente, el desarrollo psicogenético, la adaptación, la asimilación y el insigth (Hernández, 2010).

Por último, la teoría escéptica de la decisión judicial parte de la negación de la racionalidad y la objetividad del derecho. Afirma que en las decisiones no pueden controlare racionalmente, la racionalidad judicial, y por ende la objetividad son una ilusión utilizada para el cumplimiento de fines ulteriores por parte del Estado. Su tesis central afirma que la toma de decisiones judiciales obedece más a caprichos personales del operador que a un proceso que pueda justificare. El juez puede fallar de la forma caprichosa, siempre va a encontrar una forma para justificar sus decisiones, bien se manipulando hechos, acudiendo a la ley, precedente, principios del derecho o principios generales (Nieto, 1998; Salas 1998).

\subsection{Evaluación crítica}

En esta sección se argumentan tres ideas generales. Los modelos de decisión judicial son muy variados, lo cual dificulta el encontrar un modelo dominante y la decisión judicial es caso particular de la toma de decisiones humanas.

De lo descrito en la sección pasada se puede inferir que los modelos son muy variados. Bien sea porque a la ya amplia lista descrita pueden agregársele otros modelos o por las combinaciones que entre ellos pueden efectuarse.

El hecho de que existan explicaciones tan distintas hace difícil establecer un modelo dominante. Existen buenas razones, dentro de sus limitaciones específicas, para defender la fuerza de cada uno de estos modelos. Sin embargo, no puede entenderse que exista un modelo dentro de los descritos que se muestre como el dominante y que acapare las mejores explicaciones. De cierta forma, lo que ayuda a mostrar la lista reseñada es que el modelo legalista cada vez se queda con menos argumentos para entenderse como la mejor explicación entre la familia jurídica romano germana (David y Jauffret-Spinosi, 2010). Cada una de las demás teorías se constituye en buenos argumentos en contra del predominio de la creencia que la decisión judicial es un caso de derivación lógica de la decisión de unas premisas preestablecidas e irrefutables.

La decisión judicial se entiende como caso particular de las decisiones humanas. Los jueces son humanos, personas que cuentan con capacidades y limitaciones. En su diario vivir encuentran alternativas de acción, eligen entre diferentes cursos. La elección de los diferentes cursos está supeditada a diferentes recursos, deseos, información y capacidades. Igual sucede con las decisiones judiciales, dentro de un marco institucionalizado, regido por reglas, valores principios, decisiones autoritativas, debe el juez elegir entre distintos cursos de acción.

Las acciones humanas no siempre son del todo racionales. Están sujetas a diferentes limitaciones que impiden hablar de una perfecta racionalidad. No siempre 
tenemos toda la información necesaria para poder actuar, o no contamos con los recursos, o no sabemos que deseamos o como actuarán las demás personas respecto de nuestras elecciones. El juez debe elegir entre diferentes alternativas para tomar su decisión, se encuentra con las mismas limitaciones que le afectan cuando toma sus decisiones diarias. No siempre conoce todas las formas de regulación jurídica que pueden afectar un caso, no encuentra delimitado el sentido y el alcance de las normas jurídicas, tampoco conoce siempre con certeza los hechos relevantes en el proceso, ni cuenta con el tiempo suficiente para reflexionar, no puede determinar las consecuencias de su fallo, las conducta de las partes ni la precisión de los criterios del superior.

\section{TEORÍA DE LA ELECCIÓN RACIONAL}

A efectos de describir algunos aspectos de la Teoría de la Elección Racional (TER) se refiere en primer lugar el contexto de su configuración, posteriormente su estructura conceptual y luego las principales críticas que contra ella se han efectuado.

\subsection{Contexto de la TER}

El nacimiento de la TER debe partir de una previa aclaración: hay que distinguir su reflexión en cuanto forma de vida o en cuanto constructo teórico. En el primer caso, cuando se tiene en cuenta su reflexión como toma de decisiones, ha estado presente en los primeros albores de la humanidad. Ha estado ligada al hombre en una relación inescindible, la pretensión de elegir o tomar de decisiones de forma racional puede rastrearse desde la odisea y la Ilíada de Homero hasta los libros más actuales sobre nuevas tecnologías. La fragilidad del bien utilizar.

En el segundo caso, la TER como constructo teórico más o menos elaborado nació en los años cincuenta en la academia estadounidense. Especialmente se le imputa la paternidad de esta agenda investigativa a "los trabajos de Kenneth Arrow, que le valieron el Premio Nobel de Economía en 1972, pues desarrolló un poderoso edificio axiomático basado en la teoría de conjuntos para replantear un problema añejo" (Vidal, 2008, pp. 221-222).

A los trabajos de Arrow le siguieron múltiples desarrollos académicos en los cuales se plantearon versiones y aplicaciones diferentes de la naciente TER. Se resaltan especialmente los desarrollos teóricos de Elster (2007), Hirshman (1978), Schelling (1964), Shapiro (2004), Herbert (1985), Bowles (2006), Kitcher (1985), Becker (1976). Por tanto, es de esperarse que los desarrollos acerca de su fundamento, estructura y alcance, no sean armónicos y que difícilmente pueda englobarse en un concepto todas las líneas del desarrollo de lo que se ha considerado como la TER. Según Godofredo Vidal (2008) "la Teoría de la Elección Racional no es, sin embargo, un corpus monolítico. Dentro de sus límites: la premisa del interés propio como motivo fundamental de la acción humana y el individualismo metodológico, 
coexisten diversas versiones acerca del alcance -y por ende, de los límites- de la capacidad explicativa de la teoría" (pp. 221-222).

Las diferentes líneas de desarrollo de la TER han mostrado como este constructo teórico puede ser aplicado en distintos campos. Pese a que la sociología, la economía, la estadística, la psicología y la antropología han sido los campos en los que más se ha desarrollado, la capacidad aplicativa y explicativa puede encontrarse en aquellas ciencias relacionadas con el comportamiento humano como la moral, la teología y el derecho. En otras palabras "La TER es una perspectiva teórica general de las ciencias del comportamiento humano, y su ámbito es el de la interacción humana, es decir, se refiere a toda clase de situaciones sociales".

Pese lo anterior, hay que ser cautos en la utilización de la TER. No se trata de un comodín para toda clase de decisiones en cualquier campo y bajo todas las circunstancias. La capacidad instrumental de la teoría es en ocasiones inútil o complementaria. "Es importante para decisiones que no sean tan complejas" (Curzio, 1998, pp. 37-43). El pensamiento de Elster en su última etapa llegó a la conclusión que la TER no era la única forma de explicación de la conducta, a la elección racional habría que complementarse con lo que él denominó como normas sociales.

\subsection{Marco conceptual de la TER}

En el presente apartado no se pretende condensar las diferentes vertientes que se han utilizado para explicar la estructura conceptual de la TER. Tal situación desbordaría el objeto de estas páginas. Simplemente se desea establecer la forma clásica como se ha entendido los elementos esenciales de esa noción. Para ello se explica la TER con base en un tridente de elementos conectados entre sí: el individualismo metodológico, la intencionalidad y la elección racional.

El interés propio y el individualismo metodológico representan la puja entre el homo economicus, el homo sociologicus y el zoonpolitikon. Se entiende que el interés individual es la mejor forma de explicación de la conducta humana. "El interés egoísta podía ser el fundamento de un vasto edificio conceptual que pretendía ofrecer alternativas teóricas superiores a las jamás conocidas" (Vidal de la Rosa, 2008, p. 224). A ello se le suma la idea que los cambios macro pueden ser explicados de forma adecuada por cambios micro. Es decir, que las acciones humanas son los mejores candidatos para la explicación de los cambios sociales.

En segundo lugar: una acción intencional es una acción efectuada voluntariamente con la finalidad de satisfacer determinado deseo. El cumplimiento de determinado deseo, y por la naturaleza instrumental de la TER, la creencia que determinada acción lo llevan al cumplimiento del deseo, son los dos pilares de la intencionalidad. En otras palabras, la intencionalidad de la acción esta enclaustrada en la necesidad de cumplir un deseo y la creencia de que determinadas acciones lo llevarán a él (Abitbol y Botero, 2005, pp. $132-145)$. 
En tercer lugar, la elección racional se entiende como: escoger entre las diferentes alternativas de acción aquella que se crea que mejor realiza el deseo. Deseo, alternativas posibles y resultados se integran en esta noción. Se decide cuál de las acciones disponible conlleva al mejor resultado, al deseo.

Bajo esta noción se hacen importantes las características de comparabilidad, precedencia, y transitividad. El criterio de satisfacción de la finalidad por diversos mecanismos distintos lleva inmerso la capacidad de comparar los diferentes resultados. Una vez tenidos los diferentes resultados se hace necesario establecer entre ellos criterios de preferencia de conformidad con la satisfacción del deseo. La preferencia puede ser fuerte, estricta o leve. Luego, se han de ordenar los diferentes resultados de conformidad con los criterios de preferencia, transitividad.

\subsection{Críticas}

A efectos de abordar las críticas contra la TER se efectúa una categorización entre críticas específicas y críticas generales. Las primeras están referidas a cuestionamientos elaborados especialmente contra la estructura conceptual de la teoría. Las segundas están referidas a cuestionamientos relativos a que la acción individual puede explicarse con base en otros motivos, especialmente, las normas y las emociones ${ }^{5}$.

Las principales críticas efectuadas a la TER pueden resumirse en cuatro: la información es incompleta, la capacidad de computar es limitada, no tiene en cuenta la interpretación como componentes de la razones, pasa por alto que los posibles estados del mundo se den sin la acción del agente.

Difícilmente pueden encontrarse situaciones en las cuales el agente posea toda la información relevante. Muchas veces tomamos decisiones sin tener certeza de la finalidades, de los medios, de la relación entre medios y fines, etcétera. "Como nuestras creencias nunca son certezas, nuestras acciones siempre son apuestas. Por esta razón un agente racional no maximiza simplemente su utilidad, sino su utilidad esperada" (Abitbol y Botero, 2005, pp.132 - 136). Además, no siempre el agente posee la capacidad para computar la relación entre los medios y los fines, o para ver las consecuencias de los distintos cursos de acción, ello no solo se debe a que no ostenta la información necesaria, sino que no pose los conocimientos específicos, técnicos, científicos, artísticos, educativos a efectos de poder tomar la mejor decisión.

En tercer lugar, se dice que la TER no tiene en cuenta las interpretaciones como componentes de las razones por cuanto "el valor de utilidad y las probabilidades sólo representan deseos y creencias sobre la estructura causal de la situación" (Abitbol y Botero, 2005, pp. 132-145). Las interpretaciones se hacen importantes por cuanto significan la identificación del sujeto con las elecciones seguidas. La cuarta crítica manifiesta que los estados de cosas del mundo pueden darse sin necesidad de la

$5 \quad$ Esta idea se desarrollará en la tercera parte. 
acción del agente, pueden producirse por la acción y omisiones de otro agente, o de una situación externa, $y$, en ocasiones, la voluntad del agente no es suficiente para modificar los estados de cosas del mundo.

\section{LA TER EN LA DECISIÓN JUDICIAL}

En esta parte del escrito se desea efectuar una reconstrucción de las dos partes anteriores. En el apartado primero se describieron modelos de decisión judicial, en el segundo se trajeron a colación desarrollos de la TER, ahora, se quiere presentar un modelo de decisión judicial que tenga en cuenta la TER y que la muestre como caso particular de las decisiones humanas. Además de ello, se pretende mostrar como la TER en la decisión judicial se complementa con las "normas sociales de decisión".

\subsection{La imposibilidad de una teoría unitaria}

La elaboración de una teoría descriptiva de la decisión judicial es una tarea pendiente. Posner (2011) decía: "no existe un planteamiento convincente, unificado, realista y apropiadamente ecléctico de cómo los jueces adoptan realmente sus decisiones en los casos no rutinarios: dicho brevemente, falta una teoría descriptiva de la decisión judicial" (p. 42).

Tratar de establecer un modelo de decisión que explique cómo deciden los jueces, todos los jueces y en todos los casos, parece ser una tarea imposible. Las perspectivas de los modelos presentados son fundadas y dan lugar a desacuerdos razonables. Pese a ello son incompletas y, en algunos casos, sobrevaloradas.

Gran parte del error de los planteamientos existentes se debe al nivel de abstracción en el cual se tranzan. La forma de decisión es tan rica y variable que teorías con bajo nivel de abstracción no pueden agrupar de forma adecuada todos los casos que pretenden regular. Por ejemplo, la teoría sociológica sólo cabría para cuando puedan identificarse nichos afines en torno a la decisión y la teoría social cuando exista indeterminación en el derecho. Si se mostrara cómo deciden los jueces en un alto nivel de abstracción, se podrían encontrar ideas interesantes para enriquecer el debate. Entre más abstracta sea la teoría más posibilidad de cubrir todos los casos conlleva, no obstante, se corre el riesgo de alejarse demasiado de la realidad y en última instancia tornarse como inútil. Luego resulta importante buscar el punto adecuado de abstracción. La TER cuenta con esta virtud.

\subsection{La decisión judicial como caso particular de las decisiones humanas}

Además de la objeción de nivel de abstracción referida en el párrafo anterior, hay que tener en cuenta que un análisis detallado de los modelos presentados en la sección primera lleva a la inexorable conclusión que las teorías no se refiere lo mismo o no efectúan el acento en un mismo punto desde diferentes enfoques. En 
otras palabras, podría decirse que los modelos desarrollados responden a preguntas diferentes.

Las principales cuestiones que tratan las distintas teorías son las siguientes: existe la posibilidad de hablar de racionalidad en la decisión judicial, cuál es el principal camino del conocimiento, cuáles son las fuentes del argumento, en qué medida la decisión judicial es un medio para cumplir diferentes fines, cuál es la importancia de las consecuencias de la decisión judicial. Así pues, la teoría legalista ${ }^{6}$ y la escéptica hacen alusión, desde diferentes puntos a la posibilidad de la razón judicial. Responden a la pregunta si es posible o no hablar de racionalidad en la decisión del juez. Por su parte, la teoría intuicionista y la legalista, refieren a la dicotomía entre la psicología y la lógica en el momento de la solución de los problemas. La teoría legalista, actitudinal, y constitucionalista, refieren a las fuentes de la decisión judicial con distintos puntos de referencia. La teoría estratégica, sociológica, y social, muestran la labor del juez como un medio para conseguir diferentes bienes. La teoría pragmatista, estratégica y sociológica, refieren más a las consecuencias de la decisión mientras que la legalista está guiada más hacia el pasado sin consideración de las repercusiones sociales.

La labor judicial puede ser mejor entendida si se le ve como un caso particular de las decisiones humanas. Los jueces son humanos y en sus decisiones en la judicatura utilizan parámetros similares a los utilizados dentro de sus decisiones diarias. Las capacidades y limitaciones del juez son un proyecto de las capacidades y limitaciones humanas. Dentro de un marco institucionalizado los jueces en sus sentencias, no hacen otra cosa que elegir dentro de diferentes alternativas, cual es la que creen que les traerá un mejor beneficio.

El egoísmo es el principal motor que guía las decisiones judiciales. La principal finalidad que tiene el juez al obrar es el beneficio propio. La decisión que toma el juez cuando elige entre los posibles sentidos de la decisión, es aquella que él crea que le traerá mayor beneficio.

Una decisión es en beneficio individual cuando le permite mejorar, mantener o no perjudicar una situación determinada. El juez difícilmente escogería una decisión jurídica que le implique la posibilidad de ser investigado penal o disciplinariamente, o que le pueda ocasionar una multa o la pérdida de su actividad laboral. El juez toma decisiones que le permitan beneficiarse, es decir: que sus fallos no sean revocados, que el tiempo en la proyección del fallo no sea demasiado, que le dé estabilidad, que le cree una imagen positiva, aunque sea de juez promedio.

Una de las formas del obrar egoísta se da cuando el juez escoge decisiones que cree no lo perjudican. El obrar en beneficio propio lleva al juez a ajustarse principalmente a las decisiones previamente establecidas y a tratar de eludir su posible responsabilidad por una decisión equivocada, lo cual no le crea problemas y reduce su cantidad de esfuerzo. El juez que se ajusta a los postulados legalistas le

$6 \quad$ Y las demás teorías lo presuponen. 
permite resolver los conflictos de forma rápida, sin que tenga que recurrir a grandes fundamentaciones, sin muchos costos de interpretación y justificación. Apegarse a la ley significa pues una decisión benéfica.

Cuando el juez no encuentra en la ley la decisión para resolver el caso el juez encuentra la necesidad de indagar por casos similares. Ello le permite al juez buscar una norma universal para resolver el caso y tratar de eludir la responsabilidad por la decisión. El juez dice: un caso similar ya se resolvió de tal o cual manera, ahora yo resuelvo este caso de la misma forma, por cuanto la decisión del otro juez ya fue validada.

En otras palabras, lo que hace el juez es buscar la forma de eludir su responsabilidad en la toma de las decisiones, bien sea porque la decisión que tomó está basada en una disposición del legislador o en una regla de derecho de la jurisprudencia, lo importante, en todo caso, es que el juez no quiere, en la mayoría de los casos, aparecer como la persona que engendró la norma. Acudir a actos o hechos ajenos blinda la no responsabilidad.

El apego a la ley y a la jurisprudencia en la mayoría de los casos le permite al juez evitar problemas penales o disciplinares. Los jueces se apegan a la ley queriendo entre otras cosas que su conducta no se establezca o pueda ser catalogada como prevaricato. Evitan una investigación penal. Además de ello el estricto cumplimiento de los preceptos establecidos ayuda a que no sea investigado disciplinariamente por el cometimiento de faltas que no tiene el atributo de ser penales.

Esta clase de fallos le permite asimismo ahorrar tiempo en la toma de decisiones, lo que redunda en beneficio del juez. El juez gasta menos tiempo si acude a una norma preestablecida que si construye dentro el ordenamiento jurídico una norma que le permite resolver el caso; la carga argumentativa en un u otro evento es bien distinta. El juez se habilita para invertir el tiempo restante en la decisión de más casos, lo cual redundara en que será un juez más eficiente, o invertir el tiempo en su ocio, que es un bien bastante valorado.

No obstante, no todos los casos presentan un análisis tan simple, existe una variable bastante importante que tiene que ser considerada para describir la actividad del juez. La labor del juez no es enteramente racional. El juez no posee ni toda la información ni los recursos para saber cuál es la decisión que más lo beneficia. En este campo puede hablarse de una racionalidad limitada de la decisión judicial. Como se esbozó en párrafos anteriores, los jueces no poseen la información completa de las normas relevantes que regulan un conflicto, bien sea por la dispersión normativa, por la superposición de normas, por el fenómeno de la decodificación, por las regulaciones trasnacionales, por los acoples jurisprudenciales, por las micro regulaciones, etc. Ni tampoco saben a ciencia cierta cómo ocurrieron los hechos de un caso, ni qué interés legítimo existe, ni las consecuencias de sus decisiones, ni los criterios claros de decisión de los otros jueces, ni el tiempo que podaran invertir en el caso, ni la buena fe de la conducta de las partes. En gran parte, los jueces eligen con apuestas. Las sentencias en parte se construyen con base en información y recursos limitados. 
Por lo cual, se hace necesario que el juez trate de recurrir a diversas estrategias para limitar el riesgo.

Lo anterior afecta la forma simple como se han expuesto los once modelos descritos. Por ejemplo, respecto del modelo legalista, existen problemas cognitivos para fijar el sentido y alcance de algunas disposiciones, no se conocen enteramente los hechos del proceso, respecto del modelo actitudinal no se conoce a ciencia cierta cuál es la ideología detrás de todas las normas; en el caso de la teoría pragmatista no se sabe cuáles son en realidad las consecuencias de tomar determinada decisión, cómo afectará a la sociedad, los demás sistemas culturales y económicos, cómo se relaciona con otros factores, cuál es la respuesta de los demás agentes a la decisión. De forma general respecto de los presupuestos, existe falta de información fáctica y jurídica. Aunado a ello, las capacidades cognitivas del juez y su tiempo son escasos. Además, no se conocen las consecuencias de la elección, la actuación de las partes involucradas, ni las variables de los superiores. La racionalidad del juez es limitada. Se aclara que el hecho de que sea limitada no significa que sea irracional. Así como no puede pensarse que la decisión del juez obedece a criterios enteramente racionales, mal se haría en pensar que ralla con el irracionalismo, como sería una de las tesis del modelo escéptico descrito en la primera parte.

\subsection{Las normas judiciales}

Además de los elementos enriquecedores tomados de la TER para explicar la decisión judicial, existen conductas de los jueces que no parecen provenir del interés propio o no parecen ser del todo racionales, más bien parecen apegarse a una fuerza externa, tradicional que las condiciona.

Aunado al interés egoísta que guía la elección racional limitada, en ocasiones las decisiones de los jueces pueden explicarse de mejor forma mediante las normas sociales judiciales. Se acepta pues que la teoría de la elección racional puede ser complementada con otro motor de decisión: las normas sociales (Elster, 1989, 1997, 1990).

Una norma social judicial es una norma implícita en la práctica judicial que los jueces siguen de forma consciente o inconsciente por miedo a ser desaprobados directa o indirectamente. Esta clase de normas direccionan la conducta y ejercen una amplia influencia en la toma de decisiones.

Las diferencias entre las normas judiciales y la decisión judicial racional pueden plantearse en tres ideas generales. En primer lugar, las normas son más un motivante exterior mientras que la elección es interior. En segundo lugar, las normas vienen como una fuerza desde el pasado, en cambio la TER se refiere más hacia el futuro. La tercera diferencia refiere a que las normas son difíciles de cambiar, son más rígidas, mientras que la elección es más cambiable por su carácter instrumental

Las normas sociales de la decisión judicial se han construido por el transcurso del tiempo en la práctica jurídica, para la construcción de ellas se ha requerido un arduo 
trabajo judicial. Muchas de esas prácticas han sido positivizadas, pero hay otras que no necesariamente se encuentran establecidas explícitamente en los códigos -antes bien las normas sociales de decisión judicial han sido la piedra angular de las reformas procesales contemporáneas-. El hecho que hayan sido positivistas, especificadas, reglamentadas, enriquecidas, no les quita su carácter de norma social judicial.

Estas normas se constituyen en meta-normas judiciales y, como se dijo, condicionan la labor del juez. Efectuar un listado detallado de esta clase de normas no es el objeto de este escrito. Sin embargo, se hace necesario nombrar unas de ellas para resaltar su importancia. A continuación se refieren cuatro de las normas más importantes relativas a: la relación con el superior, la relación con las partes, la fundamentación mínima y la imagen del juez de cara a la sociedad.

Hay una norma que establece que se debe fundamentar la decisión de conformidad con el criterio del superior jerárquico. No es frecuente encontrar un juez que tome una decisión que "conozca" que su superior jerárquico ostenta un punto de vista distinto y quiera contradecirlo de forma directa. Por tradición, los jueces buscan fallar de conformidad con el criterio de su superior. Aunque a esta proposición se puede llegar por conducto de la decisión racional, ello se aplicaría más como una norma social que como una elección, por cuanto en distintos casos puede ser racional contradecir al superior.

Además, los jueces no pueden hacer explícito en sus sentencias que sienten más afinidad por una parte que por la otra. Es normal que los jueces sientan más empatía por uno de los sujetos procesales o que se identifique con una causa más que con otra, no obstante, esta situación no es contemplada de facto en la motivación de los fallos para la elección de la decisión. Puede decirse que existe una norma de decisión judicial que establece que los jueces deben mostrarse como imparciales en la decisión judicial.

Sin entrar en la discusión de que los beneficios y costos de la justificación de la decisión judicial, o su efectividad y legitimidad, existe una norma de decisión que dice que los jueces deben dar una apariencia de justificación de las decisiones que toman. No importa si es muy larga o corta, si es correcta o incorrecta, válida o invalidad, eficiente o ineficiente, ningún juez en estos tiempos se atrevería a tomar su decisión y no adscribirle a ella diversos argumentos, buenos o malos, lejanos o cercanos, jurídicos o extrajurídicos.

Existe una norma que dice que los jueces quieren ser reconocidos como buenos jueces. Ningún juez quiere que el adjetivo de su trabajo sea de un juez incompetente, ellos toman sus elecciones queriendo dar la imagen de ser buenos jueces, conocedores del derecho y hacedores de fallos fundados; la vanidad del juez y su nombre son componentes importantes de normas que condicionan la conducta judicial; un juez de forma consiente no tomaría una decisión que lo hiciera ver como un lego o como un desconocedor del derecho ${ }^{7}$. actitud del juez dentro del proceso y a la decisión. 


\section{CONCLUSIONES}

En este apartado se recuentan cuatro grupos de ideas relacionadas: primero, no existe actualmente una teoría descriptiva de la decisión judicial; las teorías existentes, son parciales y sobrevaloradas. Su grado de abstracción y las distintas preguntas a las que responden, las imposibilita para que una de ellas ejerza un papel dominante sobre las demás.

Por ello, en segundo lugar, se propone la TER como el mecanismo más adecuado para la explicación de la labor del juez. El interés individual se constituye en una herramienta con un potencial explicativo interesante. La decisión judicial puede verse como un caso particular e institucionalizado de las elecciones humanas.

Sin embargo, la TER encuentra límites insuperables, por lo cual se desarrolla el concepto de racionalidad acotada. Las citicas generales y específicas de la TER salpican al papel que ésta ejerce en las decisiones judiciales. Luego el mito de la entera racionalidad judicial cada vez más se encuentra en entredicho.

Como forma de complementar la TER en la decisión judicial, se propone la transpolación y reconstrucción de la noción de normas sociales judiciales. Las cuales constituyen un importante motor de actuaciones judiciales que completa el poder explicativo de la elección racional en las decisiones judiciales.

\section{REFERENCIAS}

Abitbol, P; Botero, F. (2005). Teoría de la elección racional: estructura conceptual y evolución reciente. Revista Debates actuales en los estudios políticos e internacionales (62)/ Julio-Diciembre. Bogotá: Universidad de los Andes, 132 $-145$

Alexy, R. (2002). Teoría de los derechos fundamentales. Madrid: Centro de Estudios Políticos y Constitucionales, Impreso en Solana e hijos, A.G., S.A.

Bajtin, M. (1989). Las formas de tiempo y del cronotopo en la novela, Ensayos de poética histórica, Teoría y estética de la novela. Madrid: Taurus.

Berman, H. (1996). La formación de la tradición jurídica de occidente (Mónica Utrilla, trad.) México: Fondo de Cultura Económica.

Bowles, S. (2006). Homo Economicus and Zoon Politikon, en Goodin y Tilly (Eds.), The Oxford Handbook of Contextual Politcal Analysis. Oxford: Oxford University Press.

Bulygin, E., Alchourrón, C. E. (1987). Introducción a la metodología de las ciencias jurídicas y sociales. Buenos Aires: Editorial Astrea.

Carbonell, M., Jaramillo, L. (2010). El Canon Neoconstitucional. Bogotá: Universidad Externado de Colombia.

Curzio, L. (1998). Toma de decisiones. México: Instituto Federal Electoral. 
David, R. y Jauffret - Spinosi, C. (2010). Los grandes sistemas jurídicos contemporáneos. $1^{\mathrm{a}}$ reimp., de la $11^{\mathrm{a}}$ ed., México: Universidad Nacional Autónoma de México.

Elster, J. (2007). Explaining Social Behaviour. More Nuts and Bolts for the Social Sciences. Cambridge: University Press.

Elster, J. (1989). Ulises y las sirenas: estudios sobre racionalidad e irracionalidad. México: Fondo de Cultura Económica, 1989.

Elster, J. (1997). Egonomics: Análisis de la interacción entre racionalidad, emoción, preferencias y normas sociales en la economía de la acción individual y sus derivaciones y el relato autobiográfico "Going to Chicago". Barcelona: Gedisa.

Elster, J. (1990). Tuercas y tornillos: una introducción a los conceptos básicos de las ciencias sociales. Barcelona: Gedisa.

Elster, J. (1999). Constitucionalismo y democracia. México: Fondo de Cultura Económica.

Gargarella, R.; Courtis, C. (2009). El nuevo constitucionalismo latinoamericano: promesas e interrogantes.Santiago de Chile: CEPAL.

Herbert, S. (1985). Human Nature and Politics. The Dialogue of Psychology with Political Science, American Political Science Review, (74).

Hernández, J. A. (2010). Argumentación Jurídica. México: Oxford University Press.

Hirshman, A. (1978). Las pasiones y los intereses. México: Fondo de Cultura Económica.

Kitcher, P. (1985). Vaulting Ambition. Cambridge: MIT Press.

Becker, G. (1976). The Economic Approach to Human Behavior. Chicago: University of Chicago press.

López, D. (2004). Teoría impura del derecho. La transformación de la cultura jurídica latinoamericana. Bogotá: Legis. Universidad de los Andes, Universidad Nacional.

Nieto, A. (1998). El Derecho y el revés. Barcelona: Editorial Ariel.

Nino, C. (1974). Consideraciones sobre la Dogmática Jurídica. México: Universidad Autónoma de México.

Ost, F. (1993). Júpiter, Hércules, Hermes: tres modelos de juez. Alicante. DOXA (14), 169-194.

Pashukanis, E. B. (1976). La teoría General del Derecho y el Marxismo; México: Editorial Grijalbo, S.A.

Pérez, J. A. (1996). Teorías Críticas del Derecho, en El derecho y La Justicia, Enciclopedia Iberoamericana de Justicia. Madrid: Trota.

Petev, V. (1996). Metodología y Ciencia Jurídica en el Umbral del Siglo XXI (Luis Villar Borda, trad.). Bogotá: Universidad Externado de Colombia. 
Posner, R. (2011). Cómo deciden los jueces (Victoria Roca, trad.). Barcelona: Marcial Pons.

Salas, M. (1998). ¿Qué significa fundamentar una sentencia? O del arte de redactar fallos judiciales sin engañarse a sí mismo y a la comunidad jurídica. Costa Rica: Universidad de Costa Rica.

Schelling, T. (1964). La estrategia del conflicto. Argentina: Tecnos.

Shapiro, L. (2004). Problems and Methods in the Study of Politics. Cambridge: Cambridge University Press.

Vidal, G. (2008). La teoría de la elección racional en las ciencias, sociales, en: Revista Sociológica, 23 (67), 221- 236. 
